\title{
The longitudinal mental health impact of Fukushima nuclear disaster exposures and public criticism among power plant workers: the Fukushima NEWS Project study
}

\author{
Y. Tanisho" ${ }^{1}$, J. Shigemura ${ }^{2 *}$, K. Kubota ${ }^{3}$, T. Tanigawa ${ }^{4 *}$, E. J. Bromet ${ }^{5}$, S. Takahashi ${ }^{6}$, Y. Matsuoka $^{7}$, \\ D. Nishi ${ }^{8}$, M. Nagamine ${ }^{9}$, N. Harada ${ }^{10}$, M. Tanichi ${ }^{2}$, Y. Takahashi ${ }^{6}$, K. Shimizu ${ }^{9}$, S. Nomura ${ }^{2,11}$, \\ A. Yoshino ${ }^{2}$ and Fukushima NEWS Project Collaboratorst
}

\begin{abstract}
${ }^{1}$ Health and Global Policy Institute, Chiyoda-ku, Tokyo, Japan; ${ }^{2}$ Department of Psychiatry, National Defense Medical College, Tokorozawa, Saitama, Japan; ${ }^{3}$ Department of Biostatistics, School of Medicine, Yokohama City University, Kanazawa-ku, Yokohama, Japan; ${ }^{4}$ Department of Public Health, School of Medicine, Juntendo University, Bunkyo-ku, Tokyo, Japan; ${ }^{5}$ Department of Psychiatry and Behavioral Science, Stony Brook University School of Medicine, Stony Brook, NY, USA; ${ }^{6}$ Department of Disaster Psychiatry, Faculty of Medicine, University of Tsukuba, Tsukuba, Ibaraki, Japan; ${ }^{7}$ Department of Health Care Research, Center for Public Health Sciences, National Cancer Center, Chuo-ku, Tokyo, Japan; ${ }^{8}$ Department of Mental Health Policy and Evaluation, National Institute of Mental Health, National Center of Neurology and Psychiatry, Kodaira, Tokyo, Japan; ${ }^{9}$ Division of Behavioral Science, National Defense Medical College Research Institute, National Defense Medical College, Tokorozawa, Saitama, Japan; ${ }^{10}$ Nursing Science of Community Health Care System, Department of Nursing, Tohoku University School of Health Sciences, Sendai, Japan;

${ }^{11}$ Rokubancho Mental Clinic, Japan Depression Center, Chiyoda-ku, Tokyo, Japan
\end{abstract}

Background. The Fukushima Daiichi and Daini Nuclear Power Plant workers experienced multiple stressors as both victims and onsite workers after the 2011 Great East Japan Earthquake and subsequent nuclear accidents. Previous studies found that disaster-related exposures, including discrimination/slurs, were associated with their mental health. Their long-term impact has yet to be investigated.

Method. A total of 968 plant workers (Daiichi, $n=571$; Daini, $n=397$ ) completed self-written questionnaires 2-3 months (time 1) and 14-15 months (time 2) after the disaster (response rate 55.0\%). Sociodemographics, disaster-related experiences, and peritraumatic distress were assessed at time 1. At time 1 and time 2, general psychological distress (GPD) and post-traumatic stress response (PTSR) were measured, respectively, using the K6 scale and Impact of Event Scale Revised. We examined multivariate covariates of time 2 GPD and PTSR, adjusting for autocorrelations in the hierarchical multiple regression analyses.

Results. Higher GPD at time 2 was predicted by higher GPD at time $1(\beta=0.491, p<0.001)$ and discrimination/slurs experiences at time $1\left(\beta=0.065, p=0.025\right.$, adjusted $\left.R^{2}=0.24\right)$. Higher PTSR at time 2 was predicted with higher PTSR at time $1(\beta=0.548, p<0.001)$, higher age $(\beta=0.085, p=0.005)$, and discrimination/slurs experiences at time $1 \quad(\beta=0.079$, $p=0.003$, adjusted $R^{2}=0.36$ ).

Conclusions. Higher GPD at time 2 was predicted by higher GPD and discrimination/slurs experience at time 1. Higher PTSR at time 2 was predicted by higher PTSR, higher age, and discrimination/slurs experience at time 1.

Received 8 December 2015; Revised 12 July 2016; Accepted 15 July 2016; First published online 18 August 2016

Key words: Disaster mental health, Fukushima Daiichi Nuclear Power Plant disaster, general psychological distress, Great East Japan Earthquake, post-traumatic stress disorder.

\section{Introduction}

On 11 March 2011, a 9.0 magnitude earthquake and a series of subsequent tsunamis struck the northeastern

\footnotetext{
* Address for correspondence: J. Shigemura, M.D., Ph.D.,

Department of Psychiatry, National Defense Medical College, 3-2 Namiki, Tokorozawa, Saitama 359-8513, Japan.

(Email: shige@ndmc.ac.jp) [J.S.]

(Email: tt9178tt9178@gmail.com) [T.T.]

+ Members of the Fukushima NEWS Project Collaborators are given in the Appendix.
}

coast of Japan. This disaster led to a nuclear disaster at the Tokyo Electric Power Company (TEPCO) Fukushima Daiichi Nuclear Power Plant (Daiichi). The Fukushima nuclear disaster involved a series of explosions and complete meltdowns, and proved to be the largest nuclear disaster since the 1986 Chernobyl accident. Although the Fukushima Daini Nuclear Power Plant (Daini), located $12 \mathrm{~km}$ south of Daiichi, also experienced damage from the tsunami, the situation did not escalate to the point of meltdown (Shigemura et al. 2014).

This is an Open Access article, distributed under the terms of the Creative Commons Attribution licence (http://creative commons.org/licenses/by/4.0/), which permits unrestricted re-use, distribution, and reproduction in any medium, provided the original work is properly cited. 
Research following Chernobyl and the 1979 Three Mile Island (TMI) nuclear power plant accidents showed that the release of radioactive materials, both real and perceived, created immense fear and uncertainty among the public, in part due to the invisible nature of radioactivity. Related to this fear, both accidents produced adverse mental health consequences that persisted for decades (Bromet et al. 2011). Among the workers, however, the TMI and Chernobyl studies diverged. TMI studies were conducted at multiple points within the first 4 years after the accident. Acute effects on distress were found (Kasl et al. 1981a,b), but no differences between TMI and comparison workers were noted later (Parkinson \& Bromet, 1983). No methodologically transparent studies of Chernobyl workers (referred to as liquidators) appeared until 1997, when an excess suicide mortality rate was reported in Estonian liquidators (Rahu et al. 1997), a finding extended and confirmed over time (Kasl et al. 1981a,b). An excess of diagnosable mental health disorders was also found among Ukrainian liquidators compared to controls 18 years later (Loganovsky et al. 2008).

The Fukushima nuclear power plant workers were exposed to multiple stressors at the facility, such as repeated earthquakes and tsunamis, plant explosions, and loss of colleagues. A large majority of them were local residents and thus suffered victim experience (e.g. home evacuation) or loss of family members. Some of them have also been subjected to discrimination and slurs (sabetsu and chuushou in Japanese) stemming from widespread criticism of TEPCO's postdisaster management. A cross-sectional study, conducted 2-3 month post-disaster, revealed that $29.5 \%$ of Daiichi workers v. 19.2\% of Daini workers had posttraumatic stress responses (PTSR), and that exposure to discrimination/slurs was the most significant correlate of both groups' mental health (Shigemura et al. $2012 b$ ). The longitudinal mental health effect of these workers, however, is yet to be reported.

The objective of this follow-up study is to examine whether discrimination/slurs had a sustained influence on the groups' mental health 1 year later. To our knowledge, this is the first study to longitudinally describe the mental health of a representative sample of Fukushima nuclear power plant workers.

\section{Method}

\section{Participants}

This study was conducted as a part of Fukushima NEWS Project (NEWS; Nuclear Energy Workers' Support), a longitudinal study of Daiichi and Daini workers (Shigemura et al. 2012b, 2014). Following approval by the Ethics Committees of Ehime University and National Defense Medical College, we recruited full-time employees of TEPCO who were working at Daiichi and Daini when the Fukushima accident occurred.

Fig. 1 shows flow chart of the recruitment process. At time 1 (2-3 months post-disaster, May-June 2011), questionnaires were given to 1760 workers (Daiichi, $n=1053$; Daini, $n=707$ ). Of those who received questionnaires, 405 workers were excluded due to failure to sign the consent form or returning incomplete questionnaires. Thus, time 1 data were available for 1355 respondents.

At time 2 (14-15 months post-disaster, May-June 2012), we re-recruited the original sample of TEPCO workers who continued to work at either the Daiichi or Daini nuclear power plants. Of the original 1355 workers, a total of 387 respondents did not sign the follow-up consent form, returned incomplete questionnaires, transferred from Daiichi to Daini and vice versa, transferred elsewhere after time 1, or left their job after time 1 . Thus, the final number of respondents included in the analysis was 968 (final response rate 55.0\%; Daiichi, $n=571,54.2 \%$; Daini, $n=397,56.2 \%$ ).

\section{Outcomes and measures}

We used self-report questionnaires to assess mental health status at time 1 and time 2 . The time 1 questionnaires included demographic characteristics and disaster-related stressors (coded dichotomously as 'yes' or 'no'). The disaster-related stressors were: discrimination/slurs, experience of life-threatening danger [referred to in our previous study as 'near death' (Shigemura et al. 2012b, 2014)], escape from tsunami, witness of plant explosion(s), family member death (s), colleague death(s), major property loss, home evacuation, and peritraumatic distress (PD) as measured by the Japanese version of Peritraumatic Distress Inventory (PDI). The PDI is a 13-item scale with larger numbers indicating larger psychological distress at the time of or immediately after an individual's traumatic exposure (Nishi et al. 2010).

General psychological distress (GPD) and PTSR were evaluated at both time 1 and time 2, and these variables at time 2 were our outcome variables. GPD was assessed using the Japanese version of the K6, a 6-item scale including questions on feeling 'nervous', 'hopeless', 'restless/fidgety', 'so depressed that nothing could cheer you up', 'everything was an effort', and 'worthless' in the preceding 30 days (Kessler et al. 2003; Furukawa et al. 2008). Scores ranged from 0 to 24. The scale has good internal consistency (Cronbach's $\alpha$ : time 1, 0.88; time 2, 0.89).

PTSR was assessed using the Japanese version of the Impact of Event Scale - Revised (IES-R), a 22-item scale 


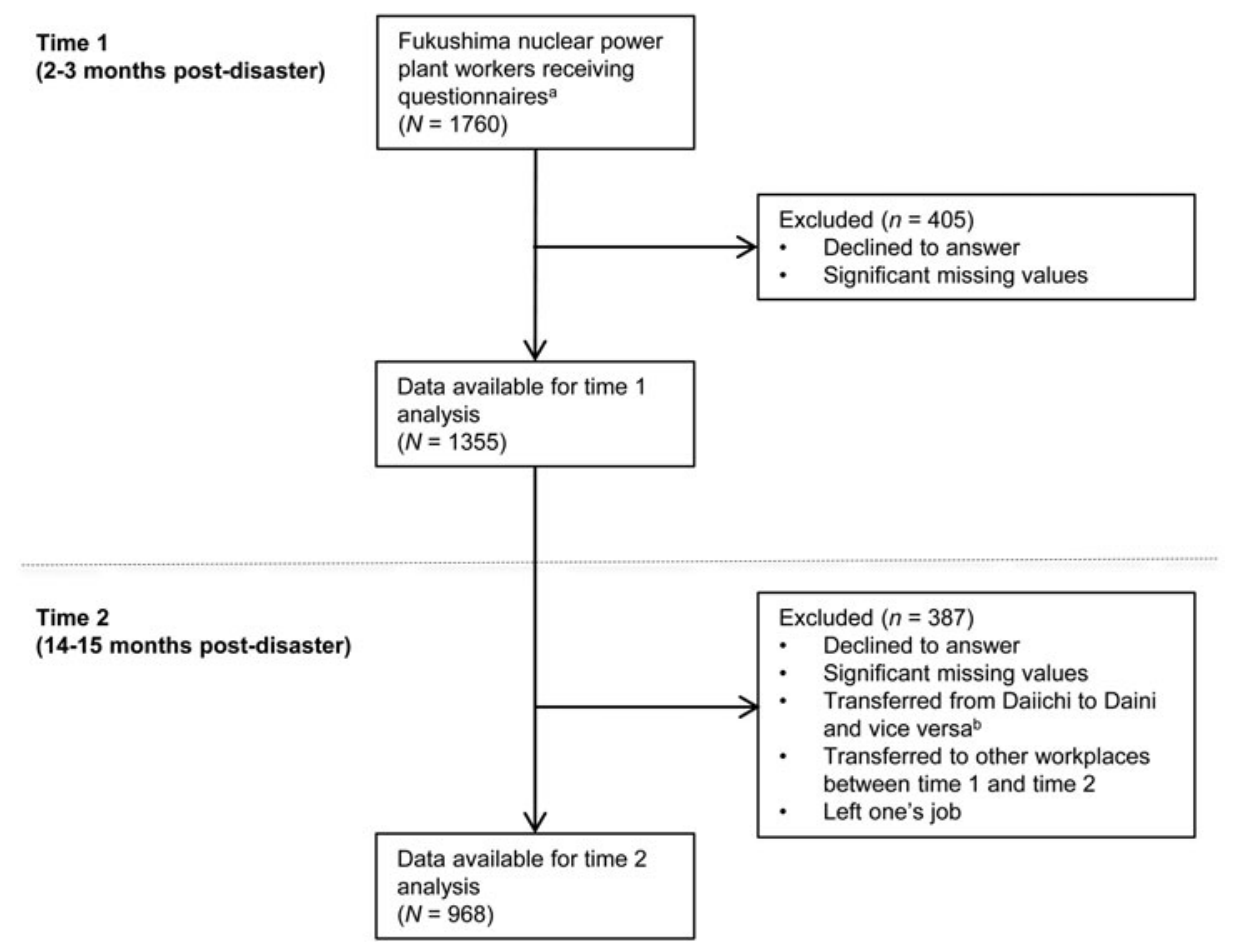

Fig. 1. Flow chart of the recruitment process. ${ }^{\text {a }}$ Full-time workers of Fukushima Daiichi and Daini nuclear power plants. ${ }^{\mathrm{b}}$ Workers who transferred from Daiichi to Daini (37 workers) and vice versa (46 workers) after time 1.

covering DSM-IV post-traumatic stress disorder (PTSD) domains of intrusion, avoidance/numbing, and hyperarousal (Weiss \& Marmar, 1997; Asukai et al. 2002). Scores ranged from 0 to 88 . The scale reliability was excellent (Cronbach's $\alpha$ : time 1, 0.95; time $2,0.95)$. PTSR refers to psychological responses of the aforementioned three domains that arise in affected individuals after a traumatic event. On the other hand, PTSD includes the three PTSR domains plus impairment and duration of at least 1 month (APA, 1994).

\section{Statistical analysis}

Demographic information and disaster-related stressors were summarized using means and standard deviations for continuous variables and percentages for dichotomous variables. We calculated the differences of time 1 variables between the study group $v$. the non-follow-up group $(n=269)$ to test the effect of attrition between time 1 and time 2 . We conducted two-way analysis of variance (ANOVA) with Bonferroni correction to examine the effect of time (time $1 v$. time 2), nuclear power plant affiliation (Daiichi $v$. Daini), and time $\times$ nuclear power plant site interaction to GPD as well as PTSR at time 2 .

We used hierarchical multiple regression analyses to identify independent predictors of GPD and PTSR at time 2. In order to assess categorical variables in the analyses, we created dummy variables ranging from
0 to 1 . The analyses process consisted of four models. At model 1, sociodemographic variables at time 1 were entered (i.e. age, gender, and pre-existing illness). For model 2, work status values at time 1 were entered (i.e. nuclear power plant affiliation, supervisory status). Regarding model 3, the following set of disasterrelated experience variables at time 1 were entered: discrimination/slurs, experience of life-threatening danger, escape from tsunami, witness of plant explosion(s), family member death(s), colleague death(s), major property loss, and home evacuation experiences. For model 4, we added mental health measures. For GPD at time 2, PD and GPD at time 1 were entered whereas for PTSR at time 2, PD and PTSR at time 1 were entered. In model 4 , we excluded PTSR at time 1 for the former and GPD at time 2 for the latter because high correlation between GPD and PTSR posed multicollinearity issues $(1<$ variance inflation factor $<5$; GPD at time $1 v$. PTSR at time 1: $r=0.79, p<0.001$; GPD at time $2 v$. PTSR at time 2: $r=0.66, p<0.001$ ).

IBM SPSS Statistics v. 22 (IBM Corp., USA) was used for the analysis. Two-tailed significance was set at $p<0.05$.

\section{Results}

Table 1 shows the workers' demographic characteristics and disaster-related experiences at time 1 . The 
Table 1. Characteristics of demographics and experiences of the participants at time 1

\begin{tabular}{lll}
\hline & \multicolumn{2}{l}{ Total $(N=968)$} \\
\cline { 2 - 3 } & $n$ & $\%$ \\
\hline Demographics & \multicolumn{2}{l}{} \\
$\quad$ Age (years) & $39.8(11.2)^{\mathrm{a}, \mathrm{b}}$ \\
Sex (male) & 909 & 93.9 \\
Pre-existing illness(es) & 139 & 14.4 \\
Nuclear power plant (Daiichi) & 571 & 59.0 \\
Supervisory work status & 92 & 9.5 \\
Disaster-related experiences & & \\
Discrimination and slurs & 131 & 13.5 \\
Experience of life-threatening danger & 380 & 39.3 \\
Escape from tsunami & 122 & 12.6 \\
Witnessing plant explosion(s) & 257 & 26.5 \\
Family member death(s) & 57 & 5.9 \\
Colleague death(s) & 168 & 17.4 \\
Major property loss & 288 & 29.8 \\
Home evacuation & 670 & 69.2 \\
Peritraumatic Distress Inventory & $17.96(9.20)^{\mathrm{a}}$ \\
\hline
\end{tabular}

Time 1, 2-3 months post-disaster.

${ }^{a}$ Mean (standard deviation).

${ }^{\mathrm{b}}$ Age at time 1 .

${ }^{\mathrm{c}}$ Daiichi nuclear power plant suffered meltdown damage. Other participants are from Daini (nearby plant, without meltdown damage).

mean age at time 1 was approximately 40 years, and more than $90 \%$ of the workers were male. About $60 \%$ of the workers were affiliated with the Daiichi plant. The workers had various disaster-related experiences. Regarding the attrition effect, the study group was older (study group $v$. non-follow-up group: $39.8 \pm$ $11.2 v$. $38.1 \pm 10.8 ; t=-2.23, p=0.026)$, had a lower percent with supervisory status $\left(9.5 \%\right.$ v. $14.1 \%, \chi^{2}=4.78$, $p=0.029)$, was less likely to report life-threatening danger $\left(39.3 \%\right.$ v. 50.6\%, $\left.\chi^{2}=11.1, p=0.001\right)$, and was more likely to report home evacuation $\left(69.2 \%\right.$ v. $56.1 \%, \chi^{2}=$ $16.1, p<0.001)$.

Table 2 displays the relationships between GPD and PTSR, time, and nuclear power plant site. The test for the main effect of time showed a significant chronological decline in the levels of GPD and PTSR (GPD: $F=221.8, p<0.001$; PTSR: $F=194.0, p<0.001)$. The test for the main effect of nuclear power plant revealed the site differences of GPD and PTSR (GPD: $F=12.9$, $p<0.001$; PTSR: $F=23.8, p<0.001)$. An interaction effect of time $\times$ nuclear power plant site was found both for GPD and PTSR (GPD: $F=10.0, p=0.002$; PTSR: $F=$ $11.2, p=0.001)$.

Table 3 represents the hierarchal multiple regression analysis of higher GPD at time 2. Model 4 explained
$24.1 \%$ of the model variance. In this model, the predictors of higher GPD at time 2 were discrimination/slurs experiences at time 1 (standardized $\beta=0.065, p=0.025$ ) as well as higher GPD at time 1 (standardized $\beta=0.491$, $p<0.001)$.

Table 4 shows the hierarchal multiple regression analysis of higher PTSR at time 2. Model 4 explained $35.5 \%$ of the model variance. In this model, higher PTSR at time 2 was associated with higher age (standardized $\beta=0.085, \quad p=0.005)$, discrimination/slurs experiences at time 1 (standardized $\beta=0.079, p=$ 0.003 ), and higher PTSR at time 1 (standardized $\beta=$ $0.548, p<0.001)$.

\section{Discussion}

Our findings indicate the mental health outcomes and their predictors of the Daiichi and the Daini workers 14-15 months after the Fukushima nuclear disaster. To our knowledge, this is the first large-scale longitudinal study to examine the year-long impact of disaster-related stress on mental health among nuclear power plant workers directly affected by the Fukushima nuclear disaster, or any other nuclear disaster of this scale.

Our data revealed GPD at time 2 was predicted by baseline GPD at time 1. Likewise, PTSR at time 2 was predicted by baseline PTSR at time 1 . These findings indicated individuals with higher mental health responses at the initial phase have risks of yearlong mental health responses. Our findings thus support the need for early mental health screenings among nuclear disaster workers. These efforts, along with interventions, might be essential to identify individuals at risk for future adverse outcomes and to mitigate their responses. Future studies will be needed to test this hypothesis.

Higher GPD and PTSR at time 2 were predicted by discrimination/slurs experience at time 1 . Studies have highlighted nuclear accidents as one of the most important challenges in emergency management, owing to the uncertainty and fear among the public (Perko, 2011). In nuclear crisis communications, one of the main public health goals is to prevent feardriven public response (Perko, 2011). When this goal not achieved, however, public responses might lead to discrimination, stigmatization, and scapegoating of certain populations (Glik, 2007). Following the Fukushima nuclear disaster, the public heavily criticized TEPCO for their post-disaster management decisions. Among the Fukushima nuclear power plant workers at both the affected (Daiichi) and unaffected (Daini) sites, discrimination and stigmatization became an issue that affected their post-disaster everyday lives (Shigemura et al. 2012a). Our result extends our 
Table 2. General psychological distress, posttraumatic stress responses, and their interactions with time and site $(N=968)$

\begin{tabular}{|c|c|c|c|c|c|c|c|c|}
\hline & \multicolumn{4}{|l|}{ K6 } & \multicolumn{4}{|c|}{ IES-R } \\
\hline & $\mathrm{df}$ & Mean square & $F$ & $p$ & $\mathrm{df}$ & Mean square & $F$ & $p$ \\
\hline \multicolumn{9}{|l|}{ Mean (standard deviation) } \\
\hline Time 1 & \multicolumn{4}{|c|}{$6.39(5.12)^{\mathrm{a}}$} & \multicolumn{4}{|c|}{$17.20(15.49)^{\mathrm{b}}$} \\
\hline Time 2 & \multicolumn{4}{|c|}{$4.02(4.01)$} & \multicolumn{4}{|c|}{$11.13(12.04)$} \\
\hline \multicolumn{9}{|c|}{ Two-way ANOVA with interaction } \\
\hline Time $^{\mathrm{c}}$ & 1 & 2425.9 & 221.8 & $<0.001^{* * *}$ & 1 & 15821.0 & 194.0 & $<0.001^{* * *}$ \\
\hline Nuclear power plant ${ }^{\mathrm{d}}$ & 1 & 400.0 & 12.9 & $<0.001^{* * *}$ & 1 & 7030.8 & 23.8 & $<0.001^{* * *}$ \\
\hline Time $\times$ nuclear power plant & 1 & 109.0 & 10.0 & $0.002^{* *}$ & 1 & 913.3 & 11.2 & $0.001^{* *}$ \\
\hline
\end{tabular}

Time 1, 2-3 months post-disaster; time 2, 14-15 months post-disaster; K6, K6 scale; IES-R, the Impact of Event Scale Revised, ANOVA, analysis of variance.

${ }^{a}$ Correlation between Peritraumatic Distress Inventory (time 1) and K6 (time 1): $r=0.68, p<0.001$.

${ }^{\mathrm{b}}$ Correlation between Peritraumatic Distress Inventory (time 1) and IES-R (time 1): $r=0.68, p<0.001$.

${ }^{\mathrm{c}}$ Time: Comparison between time 1 and time 2 .

${ }^{\mathrm{d}}$ Nuclear power plant: Comparison between Fukushima Daiichi (meltdown) and Daini (no meltdown) nuclear power plants.

${ }^{* *} p<0.01,{ }^{* * *} p<0.001$

Table 3. Prospective relationship between independent variables at time 1 and general psychological distress at time $2(N=968)$

\begin{tabular}{|c|c|c|c|c|}
\hline \multirow[b]{2}{*}{ Time 1 variables } & \multicolumn{4}{|c|}{ Time 2 K6 hierarchical models } \\
\hline & $\begin{array}{l}\text { Model } 1 \\
\text { Adjusted } \beta\end{array}$ & $\begin{array}{l}\text { Model } 2 \\
\text { Adjusted } \beta\end{array}$ & $\begin{array}{l}\text { Model } 3 \\
\text { Adjusted } \beta\end{array}$ & $\begin{array}{l}\text { Model } 4 \\
\text { Adjusted } \beta\end{array}$ \\
\hline \multicolumn{5}{|l|}{ I. Sociodemographics } \\
\hline Age & 0.045 & $0.073^{*}$ & 0.070 & 0.040 \\
\hline Gender $^{\mathrm{a}}$ & $0.072^{*}$ & $0.074^{*}$ & $0.071^{*}$ & 0.018 \\
\hline Pre-existing illness(es) ${ }^{\mathrm{b}}$ & $0.095^{* *}$ & $0.095^{* *}$ & $0.090^{* *}$ & 0.042 \\
\hline \multicolumn{5}{|l|}{ II. Work status ${ }^{\mathrm{b}}$} \\
\hline Nuclear power plant ${ }^{\mathrm{c}}$ & & -0.059 & -0.028 & 0.009 \\
\hline Supervisory status ${ }^{\mathrm{b}}$ & & $-0.087^{*}$ & $-0.074^{*}$ & -0.045 \\
\hline \multicolumn{5}{|l|}{ III. Disaster-related experiences ${ }^{\mathrm{b}}$} \\
\hline Discrimination and slurs & & & $0.140^{* * *}$ & $0.065^{*}$ \\
\hline Experience of life-threatening danger & & & 0.053 & -0.007 \\
\hline Escape from tsunami & & & 0.033 & 0.008 \\
\hline Witnessing plant explosion(s) & & & 0.015 & 0.010 \\
\hline Family member death(s) & & & -0.011 & 0.012 \\
\hline Colleague death(s) & & & 0.010 & -0.014 \\
\hline Major property loss & & & 0.048 & -0.001 \\
\hline Home evacuation & & & 0.010 & 0.001 \\
\hline \multicolumn{5}{|l|}{ IV. Mental health measures } \\
\hline PDI at time 1 & & & & -0.031 \\
\hline K6 at time 1 & & & & $0.491^{* * *}$ \\
\hline \multicolumn{5}{|l|}{ Statistics } \\
\hline Adjusted $R^{2}$ & $0.014^{* *}$ & $0.022^{* * *}$ & $0.048^{* * *}$ & $0.241^{* * *}$ \\
\hline$\Delta R^{2}$ & & 0.008 & 0.026 & 0.193 \\
\hline
\end{tabular}

PDI, Peritraumatic Distress Inventory; K6, K6 scale; time 1, 2-3 months post-disaster; time 2, 14-15 months post-disaster.

${ }^{a}$ Dummy variable was created for a categorical variable (male $=0$, female $=1$ ).

${ }^{\mathrm{b}}$ Dummy variable was created for a categorical variable $($ no $=0$, yes $=1)$.

${ }^{\mathrm{c}}$ Dummy variable was created for a categorical variable (Daiichi $=0$, Daini $=1$ ).

${ }^{*} p<0.05,{ }^{* *} p<0.01,{ }^{* * *} p<0.001$. 
Table 4. Prospective relationship between independent variables at time 1 and posttraumatic stress responses at time $2(N=968)$

\begin{tabular}{|c|c|c|c|c|}
\hline \multirow[b]{2}{*}{ Time 1 variables } & \multicolumn{4}{|c|}{ Time 2 IES-R hierarchical models } \\
\hline & $\begin{array}{l}\text { Model } 1 \\
\text { Adjusted } \beta\end{array}$ & $\begin{array}{l}\text { Model } 2 \\
\text { Adjusted } \beta\end{array}$ & $\begin{array}{l}\text { Model } 3 \\
\text { Adjusted } \beta\end{array}$ & $\begin{array}{l}\text { Model } 4 \\
\text { Adjusted } \beta\end{array}$ \\
\hline \multicolumn{5}{|l|}{ I. Sociodemographics } \\
\hline Age & $0.079^{*}$ & $0.106^{* *}$ & $0.112^{* *}$ & $0.085^{* *}$ \\
\hline Gender $^{\mathrm{a}}$ & $0.068^{*}$ & $0.074^{*}$ & $0.074^{*}$ & 0.015 \\
\hline Pre-existing illness(es) ${ }^{\mathrm{b}}$ & $0.100^{* *}$ & $0.099^{* *}$ & $0.092^{* *}$ & 0.020 \\
\hline \multicolumn{5}{|l|}{ II. Work status ${ }^{\mathrm{b}}$} \\
\hline Nuclear power plant ${ }^{\mathrm{c}}$ & & $-0.106^{* *}$ & $-0.066^{*}$ & -0.002 \\
\hline Supervisory status ${ }^{\mathrm{b}}$ & & $-0.086^{*}$ & $-0.073^{*}$ & -0.035 \\
\hline \multicolumn{5}{|l|}{ III. Disaster-related experiences ${ }^{\mathrm{b}}$} \\
\hline Discrimination and slurs & & & $0.192^{* * *}$ & $0.079^{* *}$ \\
\hline Experience of life-threatening danger & & & 0.045 & -0.035 \\
\hline Escape from tsunami & & & $0.065^{*}$ & 0.019 \\
\hline Witnessing plant explosion(s) & & & 0.042 & 0.031 \\
\hline Family member death(s) & & & 0.037 & 0.038 \\
\hline Colleague death(s) & & & 0.038 & 0.008 \\
\hline Major property loss & & & 0.024 & -0.023 \\
\hline Home evacuation & & & 0.010 & -0.002 \\
\hline \multicolumn{5}{|l|}{ IV. Mental health measures } \\
\hline PDI at time 1 & & & & 0.024 \\
\hline IES-R at time 1 & & & & $0.548^{* * *}$ \\
\hline \multicolumn{5}{|l|}{ Statistics } \\
\hline Adjusted $R^{2}$ & $0.020^{* * *}$ & $0.036^{* * *}$ & $0.089^{* * *}$ & $0.355^{* * *}$ \\
\hline$\Delta R^{2}$ & & 0.016 & 0.053 & 0.266 \\
\hline
\end{tabular}

PDI, Peritraumatic Distress Inventory; IES-R, the Impact of Event Scale Revised; time 1, 2-3 months post-disaster; time 2, 14-15 months post-disaster.

${ }^{\text {a }}$ Dummy variable was created for a categorical variable (male $=0$, female $=1$ ).

${ }^{\mathrm{b}}$ Dummy variable was created for categorical variables (no $=0$, yes $=1$ ).

${ }^{\mathrm{c}}$ Dummy variable was created for a categorical variable (Daiichi $=0$, Daini $\left.=1\right)$.

${ }^{*} p<0.05,{ }^{* *} p<0.01,{ }^{* * *} p<0.001$.

previous cross-sectional report (Shigemura et al. 2012b) and suggest that negative public responses have a sustained mental health impact on these workers.

In this study, PTSR at time 2 was predicted by older age. This suggests that older workers are more prone to develop PTSR than younger workers. To our knowledge, there is only one study finding regarding the relationship between age and mental health among nuclear power plant workers; a mental health study among TMI workers showing that age was not a contributing factor for their post-disaster mental health (Parkinson \& Bromet, 1983). It suggests that our study shows novel findings and importance of support to older workers, but further investigation is needed for more in-depth analysis.

PD at time 1 was not significantly associated with either GPD or PTSR at time 2. There is compelling evidence in the literature showing that emotional distress during a traumatic event is a strong predictor of objective severity of the event. This association was reported following a natural disaster (Cénat \& Derivois, 2014) and in armed conflict survivors (Agorastos et al. 2013) as well as in first responders such as police officers (Marmar et al. 2006) and rescue workers (Nishi et al. 2012). In our time 1 cross-sectional report (Shigemura et al. 2014), PD mediated the association between traumatic exposure and PTSR. In this report, however, we were unable to show a definite relationship between PD and mental health responses at time 2, and this result might be due to high correlations between time 1 PD, GPD, and PTSR. We do not know of any other longitudinal studies assessing this relationship among the nuclear power plant workers immediately following a disaster. Additional studies are needed to understand the role of PD and subsequent mental health responses among this population. 


\section{Strengths and limitations}

There are several study limitations that must be considered in evaluating the results of the current study. First, the sample consists of employees from a single company, but there are several companies that staff the Fukushima nuclear power plants. Thus, our study findings do not represent all of the Fukushima nuclear power plant workers. Second, this study was assessed using self-report questionnaires rather than interviews. Third, we did not assess some demographic variables (e.g. marital status, income, presence or absence of children, detailed job descriptions) that might also have been associated with the psychological outcomes. Fourth, workers who were not in the follow-up had different demographics than the study group, such as higher rate of life-threatening experience. We do not know the reasons of non-follow-up at time 2, and caution should be exercised in generalizing from the results. Fifth, given that approximately 1 year had passed since the disaster exposure when the follow-up questionnaires were administered, other potential traumatic events may have contributed to the outcomes. Last, there is little evidence about the physical and/or mental health influence of their radiation exposure. There has been no acute radiation syndrome or any other serious radiation-related health crisis to the Fukushima nuclear power plant workers during this time period (Hiraoka et al. 2015; Shimura et al. 2015). Still, more potential predictors should be included in future studies of nuclear power plant workers after major meltdowns as happened in Fukushima.

The current study also has a number of offsetting strengths, including a unique sample as well as the 1-year follow-up design. To our knowledge, this is the first study to clarify the temporal association between discrimination/slurs and mental health status among nuclear power plant workers following a large-scale nuclear disaster.

\section{Conclusion}

Among the Fukushima nuclear power plant workers post-nuclear disaster, the predictors of higher GPD at time 2 were: higher GPD at time 1 and discrimination/ slurs experience at time 1 . The predictors of higher PTSR at time 2 were: higher PTSR at time 1, discrimination/slurs experience at time 1, and older age. Early mental health screenings and interventions might be helpful to identify at-risk individuals and to provide intervention programmes. Considering findings that discrimination/slurs significantly influence the longterm mental health of these workers, strategies to reduce public criticism are likely to reduce emergence of negative mental health outcomes. Careful mental health support for older workers might also need to be considered. Further investigation is essential for more insightful analysis of the long-term mental health of this population.

\section{Appendix. Fukushima NEWS Project Collaborators}

Shoichi Tachibana, M.D., Ph.D. ${ }^{1,2}$, Shin-ya Sano, M.D., Ph.D. ${ }^{3}$, Chiyo Fujii, M.D., Ph.D. ${ }^{4}$, Tatsuro Kuwahara, M.D., Ph.D. 5,6, Yasutaka Tatsuzawa, M.D., Ph.D. , Yutaka Sato, MA ${ }^{5}$, Hiroyuki Toda, M.D., Ph.D. ${ }^{5}$

${ }^{1}$ Division of Environmental Medicine, Defense Medicine Research Institute, National Defense Medical College, Tokorozawa, Saitama Japan

${ }^{2}$ Hirasawa Memorial Hospital, Tokorozawa, Saitama, Japan ${ }^{3}$ Department of Psychology, National Defense Medical College, Tokorozawa, Saitama Japan

${ }^{4}$ Department of Psychiatric Rehabilitation, National Institute of Mental Health, National Center of Neurology and Psychiatry, Kodaira, Tokyo Japan

${ }^{5}$ Department of Psychiatry, National Defense Medical College, Tokorozawa, Saitama Japan

${ }^{6}$ Department of Psychiatry, Tachikawa Hospital, Tachikawa, Tokyo Japan

\section{Acknowledgements}

This work was partly supported by Health and Labour Sciences Research Grants (Research on Occupational Safety and Health H24-001, 25-H24-001, 26-H24-001) from the Ministry of Health Labour and Welfare of Japan and a Naval International Cooperative Opportunities Research Grant from the US Office of Naval Research Global and by GHIPP at National Graduate Institute for Policy Studies. The funders had no role in the design and conduct of the study; data collection, management, analysis, and interpretation of the data; preparation, review, or approval of the manuscript; or decision to submit the manuscript for publication. The authors thank Dr Hiromi Murakami (Center for Strategic and International Studies and Health and Global Policy Institute) for her support and Dr Kiyoshi Kurokawa for his advice and encouragement [principal investigator of Global health Innovation Policy Program (GHIPP)] at the National Graduate Institute for Policy Studies (grips. ac.jp/en/), Health and Global Policy Institute, and Chair of Fukushima Nuclear Accident Independent Investigation Commission by the National Diet of Japan (naiic.go.jp). We are indebted to Ms. Tomoko Yamamoto, R.N. (TEPCO Fukushima Daini Nuclear Power Plant), Ms. Mariko Tanaka, R.N. (TEPCO Fukushima Daiichi Nuclear Power Plant), Ms. Yoshiko Kage (TEPCO R\&D Center), Dr Hiroshi Kikuchi (TEPCO Head Office), and the medical team 
staff of Daiichi, Daini, as well as the TEPCO Head Office for their cooperation and support. We deeply thank the plant workers for their research participation, bravery and dedicated recovery efforts.

\section{Declaration of Interest}

Jun Shigemura, Takeshi Tanigawa, Sho Takahashi, Soichiro Nomura, and Aihide Yoshino provided mental health assistance to the workers of Tokyo Electric Power Company (TEPCO) Fukushima Daiichi and Daini Nuclear Power Plants according to official requests from Daini and a Japanese government cabinet order to the Ministry of Defense. Takeshi Tanigawa is employed part-time by TEPCO Fukushima Daini Nuclear Power Plant asan occupational physician. Sho Takahashi is a part-time psychiatrist for TEPCO Hirono Power Station. All other authors declare that they have no conflicts of interest. The views expressed in the manuscript are those of the authors and donot reflect the views or policies of the authors' institutions, TEPCO, the funders, the Japanese government or any of its sub-agencies.

\section{References}

Agorastos A, Nash WP, Nunnink S, Yurgil KA, Goldsmith A, Litz BT, Johnson H, Lohr JB, Baker DG (2013). The Peritraumatic Behavior Questionnaire: development and initial validation of a new measure for combat-related peritraumatic reactions. BMC Psychiatry 13, 9.

APA (1994). Diagnostic and Statistical Manual of Mental Disorders, 4th edn. American Psychiatric Association: Washington, DC.

Asukai N, Kato H, Kawamura N, Kim Y, Yamamoto K, Kishimoto J, Miyake Y, Nishizono-Maher A (2002). Reliability and validity of the Japanese-language version of the Impact of Event Scale - Revised (IES-R-J): four studies of different traumatic events. Journal of Nervous and Mental Disease 190, 175-182.

Bromet EJ, Havenaar JM, Guey LT (2011). A 25 year retrospective review of the psychological consequences of the Chernobyl accident. Journal of Clinical Oncology 23, 297-305.

Cénat JM, Derivois D (2014). Assessment of prevalence and determinants of posttraumatic stress disorder and depression symptoms in adults survivors of earthquake in Haiti after 30 months. Journal of Affective Disorders 159, 111-117.

Furukawa TA, Kawakami N, Saitoh M, Ono Y, Nakane $Y$, Nakamura $Y$, Tachimori H, Iwata N, Uda H, Nakane $H$, Watanabe M, Naganuma Y, Hata Y, Kobayashi M, Miyake Y, Takeshima T, Kikkawa T (2008). The performance of the Japanese version of the K6 and K10 in the World Mental Health Survey Japan. International Journal of Methods in Psychiatric Research 17, 152-158.

Glik DC (2007). Risk communication for public health emergencies. Annual Review of Public Health 28, 33-54.
Hiraoka K, Tateishi S, Mori K (2015). Review of health issues of workers engaged in operations related to the accident at the Fukushima Daiichi Nuclear Power Plant. Journal of Occupational Health 57, 497-512.

Kasl SV, Chisholm RF, Eskenazi B (1981a). The impact of the accident at the Three Mile Island on the behavior and wellbeing of nuclear workers; part I: perceptions and evaluations, behavioral responses, and work-related attitudes and feelings. American Journal of Public Health 71, 472-483.

Kasl SV, Chisholm RF, Eskenazi B (1981b). The impact of the accident at the Three Mile Island on the behavior and wellbeing of nuclear workers: part II: job tension, psychophysiological symptoms, and indices of distress. American Journal of Public Health 71, 484-495.

Kessler RC, Barker PR, Colpe LJ, Epstein JF, Gfroerer JC, Hiripi E, Howes MJ, Normadn SL, Manderscheid RW, Walters EE, Zaslavsky AM (2003). Screening for serious mental illness in the general population. Archives of General Psychiatry 60, 184-189.

Loganovsky K, Havenaar JM, Tintle NL, Guey LT, Kotov R, Bromet EJ (2008). The mental health of clean-up workers 18 years after the Chernobyl accident. Psychological Medicine 38, 481-488.

Marmar CR, McCaslin SE, Metzler TJ, Best S, Weiss DS, Fagan J, Liberman A, Pole N, Otte C, Yehuda R, Mohr D, Neylan T (2006). Predictors of posttraumatic stress in police and other first responders. Annals of the New York Academy of Sciences 1071, 1-18.

Nishi D, Koido Y, Nakaya N, Sone T, Noguchi H, Hamazaki K, Hamazaki T, Matsuoka Y (2012). Peritraumatic distress, watching television, and posttraumatic stress symptoms among rescue workers after the Great East Japan earthquake. PLoS ONE 7, e35248.

Nishi D, Matsuoka Y, Yonemoto N, Noguchi H, Kim Y, Kanba S (2010). Peritraumatic Distress Inventory as a predictor of post-traumatic stress disorder after a severe motor vehicle accident. Psychiatry and Clinical Neurosciences 64, 149-156.

Parkinson DK, Bromet EJ (1983). Correlates of mental health in nuclear and coal-fired power plant workers. Scandinavian Journal of Work, Environment \& Health 9, 341-345.

Perko T (2011). Importance of risk communication during and after a nuclear accident. Integrated Environmental Assessment and Management 7, 388-392.

Rahu M, Tekkel M, Veidebaum T, Pukkala E, Hakulinen T, Auvinen A, Rytömaa T, Inskip PD, Boice Jr. JD (1997). The Estonian study of Chernobyl cleanup workers: II. Incidence of cancer and mortality. Journal of Radiation Research 147, 653-657.

Shigemura J, Tanigawa T, Nishi D, Matsuoka Y, Nomura S, Yoshino A (2014). Associations between disaster exposures, peritraumatic distress, and posttraumatic stress responses in Fukushima nuclear power plants workers following the 2011 nuclear accident: the Fukushima NEWS project study. PLOS ONE 9, e87516.

Shigemura J, Tanigawa T, Nomura S (2012a). Launch of mental health support to the Fukushima Daiichi nuclear power plant workers. American Journal of Psychiatry 169, 784. 
Shigemura J, Tanigawa T, Saito I, Nomura S (2012b). Psychological distress in workers at the Fukushima nuclear power plants. Journal of American Medicine Association 308, 667-669.

Shimura T, Yamaguchi I, Terada H, Okuda K, Svendsen ER, Kunugita N (2015). Radiation occupational health interventions offered to radiation workers in response to the complex catastrophic disaster at the Fukushima Daiichi Nuclear Power Plant. Journal of Radiation Research 56, 413-421.

Weiss DS, Marmar CR (1997). The impact of event scalerevised. In Assessing Psychological Trauma and PTSD (ed. J. P. Wilson and T. M. Keane), pp. 399-411. The Guilford Press: New York. 